\title{
Understanding Volunteer-Led 4-H Programs ${ }^{1}$
}

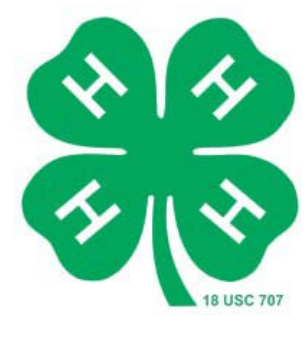

Bryan D. Terry ${ }^{2}$

\section{Guiding Principles}

Youth development in Florida is guided by a set of principles. Fundamentally, Florida 4-H is:

- $\quad$ Based in the community with needs determined locally.

- $\quad$ Coordinated and managed by the professional staff of the University of Florida.

- Led by volunteers under the guidance of Extension professionals and staff.

- $\quad$ Supported by the land-grant university research base (UF/IFAS 4-H Youth Development, 2001).

In order for the local 4-H youth development program to meet the local needs of its community, 4-H agents must understand and be able to communicate these principles. Two of these principles are often misunderstood and need further clarification.

\section{4- $\mathrm{H}$ is \\ Supported by Professional Extension Staff}

The role of the professional 4-H agent is often misunderstood (Sinasky \& Bruce, 2006). The uncertainty arises from (1) the fact that effective youth development requires management and (2) the need for Extension professionals to be educators. These two requirements are not mutually exclusive. That is, there is a management component to education as well as an education component to management.

\section{Management in Education}

Successful organizations, including 4-H, are managed for effectiveness (Thompson \& Strickland, 2003). Management is the development of a strategy that allocates resources to meet a goal or objective (Booth \& Rowlinson, 2006). Effectiveness, with respect to organizations, has been defined as the ability of an organization to accomplish its goals and objectives through competent management of people, processes, money, time, and information (Powell, 2006). Management theory has typically identified four functions of competent management: (1) planning, (2) organizing, (3) leading, and (4) controlling (Fayol, 1949; Carroll \& Gillen, 1987; Booth \& Rowlinson, 2006).

Planning produces fundamental decisions and actions that shape and guide what an organization is, what it does, and why it does it. It requires broad-scale information gathering, an exploration of alternatives, and an emphasis on the future implications of present decisions. Strategic planning is a process. It includes: (1) developing and analyzing the organization's mission and goals, (2) identifying general strategies, (3) setting objectives, and (4) allocating resources (Camp, 1993).

Organizing includes a broad set of activities, and has been considered one of the major functions of management (Carroll \& Gillen, 1987). McNamara (n.d.) described the management function of organizing as "the

${ }^{1}$ This document is 4-H 6.1, one of a series of the Florida 4-H Program, Florida Cooperative Extension Service, Institute of Food and Agricultural Sciences, University of Florida. Please visit the Florida 4-H Web site at http://4h.ifas.ufl.edu

2

Bryan D. Terry, assistant professor, Department of Family, Youth and Community Sciences; Institute of Food and Agricultural Sciences; University of Florida; Gainesville 32611.

The Institute of Food and Agricultural Sciences (IFAS) is an Equal Employment Opportunity Institution authorized to provide research, educational information and other services only to individuals and institutions that function with non-discrimination with respect to race, creed, color, religion, age, disability, sex, sexual orientation, marital status, national origin, political opinions or affiliations. U.S. Department of Agriculture, Cooperative Extension Service, University of Florida, IFAS, Florida A. \& M. University Cooperative Extension Program, and Boards of County Commissioners Cooperating. The Florida 4-H Program is the youth development program of the Florida Cooperative Extension Service/Institute of Food and Agricultural Sciences/University of Florida/Millie Ferrer, Interim Dean. 
activities to collect and configure resources in order to implement plans in a highly effective and efficient fashion." Producing value is about coordinating an organization's resources, processes, and activities that are appropriate in the environment in which the business operates (Blanchard \& Hersey, 1993).

Organizational success is often determined by the quality of leadership that is exhibited. Leadership is a process by which a person motivates others to accomplish an objective and directs in a way that makes it more cohesive and coherent (Burns, 1978). 4-H must be able to motivate volunteers to an elevated goal and direct them to the duties or responsibilities assigned during the planning process (Allen, 1998). The basis of good 4-H leadership is honorable character and selfless service to your organization. In your volunteers' eyes, your leadership encompasses everything you do that effects the 4-H objectives, and their own wellbeing. Respected leaders concentrate on what they are [be] (such as beliefs and character), what they know (such as job, tasks, and human nature), and what they do (such as implementing, motivating, and providing directions).

Control is the process through which standards for performance of people and processes are set, communicated, and applied. The process that guarantees plans are being implemented properly is the controlling process. Control allows for ease of delegating tasks to team members and as managers may be held accountable for the performance of subordinates, they may be wise to extend timely feedback of employee accomplishments. (Allen, 1998).

\section{Education in Management}

A key concept in the management of $4-\mathrm{H}$ programs is the education that occurs. 4-H agents in Florida often utilize staff and volunteers to manage the activities and events that are experienced by youth. If it is true that effective management includes planning, organizing, leading, and controlling, then all staff and volunteers need the skills necessary to be effective managers.

It is through education delivered by the 4-H agent that staff and volunteers improve their competencies. Staff and volunteers need skills to manage people, processes, money, time, and information. Competencies include:

- The ability to create, deliver and interpret information effectively through formal and nonformal means.

- The ability to engage others in planning, providing and delivering positive $4-\mathrm{H}$ youth development programming in a community.

- Utilization of appropriate policies, procedures and safety guidelines, when acting on behalf of Extension.

- The ability to plan, implement and evaluate research-based learning opportunities that promote positive youth development.

- The ability to intentionally and appropriately apply the principles and best practices that result in positive youth development.

- The ability to develop effective relationships, work competently with individuals and groups, and express empathy and understanding for others.

\section{4-H is Led by Volunteers}

Another principle that should guide the 4-H program is that it is led by volunteers and supported by Extension professionals and staff. Although no formal definition for what is meant by "volunteer led", to lead means to motivate and direct (Slover, 2007). Guidance and direction in 4-H is provided through the advisory committee, expansion and review committee, project committees, county councils, and other stakeholders. However, guidance and direction is also applicable to management of the $4-\mathrm{H}$ program.

4-H does make a difference in the lives of young people in the community. Research in

March 2009 
Florida has shown that over $50 \%$ of the youth outcomes achieved by youth are the result of direct involvement of a volunteer (Jordan \& Fogarty, 2006). There are a number of good reasons for having a volunteer-led 4-H program. Volunteer-led programs (1) allow for expansion of the 4-H program, (2) provide for program consistency, and (3) provide program stability.

Quality 4-H programs require multiple delivery methods to adequately meet the developmental needs of youth and volunteers. Ensuring that these experiences are safe and appropriate for youth requires coordination, management, and resources. One of the limiting factors for county 4-H programs in Florida is resources. This includes not only human resources, but also financial resources.

Balancing one's personal life and establishing and maintaining a quality $4-\mathrm{H}$ program is nearly impossible with only the resources of the county 4-H office.

Utilizing volunteers in advisory committees, middle management, and direct service to youth leverages paid staff to accomplish more. This includes planning, implementing and managing events, developing financial resources, and developing partnerships and relationships with other organizations.

Volunteer-led 4-H programs provide consistency. Consistency refers to the ability to replicate under similar conditions at a later time. This will ensure that policies, procedures, and curriculum will have the best likelihood of success. Consistency does not mean that each $4-\mathrm{H}$ program will utilize the same delivery methods and techniques. It does suggest however, that 4-H faculty, staff, and volunteers understand and utilize its guiding principles.

One of the attributes of Extension staffing is the opportunity to transition into new roles. It is understandable that an Extension 4-H agent might want to advance their career by moving to another county or assuming a different role. Departure of the 4-H agent in a county may lead to a decline in the quality of service delivered through $4-\mathrm{H}$. Volunteer-led 4-H programs provide stability that not only enhances the organization, but also maintains the quality of service delivered and expected by youth that participate in our programs.

\section{Elements of Volunteer-Led 4-H Programs}

Successful organizations (1) establish a culture that facilitates fulfillment of the organizational mission, vision, and objectives; (2) develop a structure that communicates and coordinates the organization's functions; (3) create processes that that allow for strategy implementation; and, (4) deploy resources efficiently and effectively to accomplish organizational goals and objectives (Thompson and Strickland, 2003). Given that volunteers are a key element in the success of $4-\mathrm{H}$, it is necessary for the 4-H agent to create learning environments, structure, process, and resources to support volunteers.

Culture is a set of learned beliefs, values, and behaviors that are shared by the members of a group, organization, or society. There are two points to this definition that are important for volunteer-led 4-H programs. First, culture is learned. Learning is an outcome of the educational process, and, coincidentally, one of our responsibilities as extension agents. Next, culture is shared. An important component of sharing is communication. Two-way communication must exist between administration, volunteers, and county faculty and staff. The 4-H agent must facilitate and teach the communication process to establish culture. Just as $4-\mathrm{H}$ agents teach members and volunteers the culture of Extension and 4-H in its traditions, history, and methodology, it is important to communicate the culture of volunteer-led programs.

Organizational structure is the way in which the interrelated groups of an organization are constructed. From a managerial point of view, the main concerns are ensuring effective communication and coordination of the organizational functions to achieve goals and objectives (Robbins, 1987). In 4-H, the organizational structure includes paid faculty and staff, volunteers, and youth, as well as those in stakeholder roles both internal and external to the University of Florida. 
What separates successful volunteer organizations from the others is not just the product or service delivered, but the structure that supports operation. Effective organizations have identified the key leadership and management roles that are necessary for success, identified the roles and responsibilities for each role, and actively recruit qualified individuals to fill these roles. In addition, these roles are communicated to other members of the organization and are visible on an organizational chart.

For 4- $\mathrm{H}$, this suggests that a structure is necessary for program management functions as well as educational delivery functions. Successful volunteer-led 4 -H programs have identified leadership roles, management roles, and directservice roles for volunteers. Therefore, the volunteer position description becomes one of the most important criteria of program management and education delivery. To be successful, it is necessary to match the interests, skills, and abilities of a volunteer with an appropriate role in the 4-H program. Creating a well developed organizational chart will help identify the leadership, management, and direct-service roles.

Processes refer to the strategy of achieving goals and objectives. UF/IFAS Extension and Florida 4-H have adopted the ISOTURE model as its strategy to involve volunteers in fulfilling its mission. ISOTURE is a volunteer management model that, when implemented, helps 4-H agents:

- Identify roles for 4-H volunteers

- Select the appropriate volunteer for each identified role.

- Orient volunteers on the philosophy and structure of 4-H and their role in 4- $\mathrm{H}$.

- Train volunteers to be successful in their chosen 4-H role.

- Utilize volunteers according to their roles.

- Recognize volunteers for their service.

- Evaluate volunteer activity for program improvement and enhancement (Boyce, 1971).

Key to this strategy is its implementation. Start by identifying one activity/event and use the ISOTURE model to increase the involvement of volunteers.
Resources refer to people, time, money, and educational materials that are needed to accomplish established goals and objectives. As stated earlier, it is nearly impossible to rely on the resources of the local county 4-H office alone. What is important to understand about resources, is not what or how much the program has, it is how efficiently the existing resources are used. A good organizational structure will not only help develop resources, but will utilize these resources in the most efficient manner.

\section{An Example}

A good way to illustrate the concept of a volunteer-led program is to relate it to one that exists in Extension. The Master Gardener program is considered a viable delivery model by Extension administration and has established value in local communities. In the Extension Master Gardener program, professional faculty and staff provide education to a set of volunteers through workshops, educational materials, and consultations. These volunteers then either train and manage other volunteers or provide direct service to residents in a local community.

When you think about it further, nobody in Extension questions the horticulture agent about their educational role, nobody questions whether it is appropriate for Master Gardener volunteers to train and manage other volunteers, and nobody questions the value of the direct services that these volunteers provide. This illustrates the concept of culture.

Master Gardener programs also have an established structure. The program has identified its leadership, management, and direct service roles and then recruited volunteers to fill these roles. Volunteers are utilized to recruit, manage, and train other volunteers and their volunteers are loyal and committed. This is the direct result of matching the interest, skills, and abilities of a volunteer with an appropriate role in the program.

A little less clear is the consistency in which Master Gardener programs utilize a process model. Many have attended the ISOTURE training offered in 4-H, while others have used other methods to involve volunteers. What is clear is that they have recruited and utilized volunteers successfully. 
There is no question that the program has generated resources and these resources are used to accomplish the program objectives. Master Gardener programs usually have their own office, computer equipment, and office supplies. In addition, they have access to research-based educational materials and they know how to use it to solve client problems.

\section{Conclusion}

Volunteer-led programs are the best opportunity for 4-H to expand youth development into the community. Florida has all of the elements necessary to establish and maintain a volunteer-led 4-H program. The concept is consistent with the culture of Extension. The tools necessary to develop a structure are available. The ISOTURE model is a well established strategy to involve volunteers. Finally, the 4-H program has quality curriculum and state support to facilitate volunteer led 4-H programs.

\section{References}

Allen, G. (1998). In Supervision. Retrieved October, 22, 2007, from http://ollie.dcccd.edu.

Blanchard, K H. \& Hersey, P. (1993). Management of Organizational Behavior (6th ed.). Englewood Cliffs: NJ: Prentice-Hall, 3-11.

Booth, C. \& Rowlinson, M. (2006). Management and organizational history: Prospects. Management and Organizational History, 1(1).

Boyce, M. V. (1971). A systematic approach to leadership development. Washington, DC: USDA, Extension Service. (ERIC Document Reproduction Service No. ED 065 793).

Burns, J. (1978). Leadership. New York: Harper \& Row.

Camp, R. C. (1993). Benchmarking: The search for industry best practices that lead to superior performance. Norcross, GA: Industrial Engineering and Management Press.

Carroll. S. J. \& Gillen, D. J. (1987). Are the Classical Management Functions Useful in
Describing Managerial Work? The Academy of Management Review 12(1), 38-51.

Fayol, H. (1949). General and Industrial Management. London, England: Pittman.

McNamara, C. (n.d.). Management Function of Organizing: Overview of Methods. Retrieved July 3, 2007, from http://www.managementhelp.org

Powell, R. M. (2006). Lines of Excellence. Air and Space Power Journal.

Robbins, S. P. (1987). Organization theory: structure, design, and applications. Hemel Hempstead: Prentice Hall.

Sinasky, M. E. \& Bruce, J. A. (2006). Supervisors' and 4-H Youth Development Educators' Perceptions of the Leadership Practices Employed by Educators. Journal of Extension, 44(3).

Slover, D. J. (2007). U.N.I.Q.U.E.: Growing the Leader Within. Albany, OR: Leader Garden Press.

Thompson, A. A. Jr. \& Strickland, A. J. (2003). Strategic Management: Concepts and Cases (Thirteenth ed.). New York: McGraw-Hill.

UF/IFAS 4-H Youth Development. (2001). 4-H Volunteer Development and Management. In J. C. Jordan (Ed.), 4-H Program Handbook. Gainesville, FL: UF/IFAS Extension. 